\title{
Infantile Pompe disease treatment with Myozyme in Chaharmahal and Bakhtiari: A case report
}

\author{
Nabiollah Asadpour ${ }^{\mathbb{D}}$, Najmeh Bagheri-Kakolaki ${ }^{\circledR}$ \\ 'Department of Pediatrics, Shahrekord University of Medical Sciences, Shahrekord, Iran \\ ${ }^{2}$ School of Medicine, Shahrekord University of Medical Sciences, Shahrekord, Iran
}

*Corresponding Author: Najmeh Bagheri-Kakolaki, School of Medicine, Shahrekord University of Medical Sciences, Shahrekord, Iran. Tel: +983833351031, Email: naba2021@yahoo.com

\begin{abstract}
Pompe disease is a lysosomal storage disorder that results from an inborn error of metabolism which involves abnormal glycogen storage. Infantile-onset Pompe disease is the most severe phenotype that manifests with the findings of hypotonia, generalized muscle weakness, feeding difficulties, a failure to thrive, hearing loss, hypertrophic cardiomyopathy with systolic dysfunction, and respiratory distress. There is no effective treatment for Pompe disease and clinical control includes primary support health care. However, recent studies have reported that enzyme replacement therapy (ERT) can effectively decrease the symptoms or severity of the disease. The present study is a case report of a 24-day patient with infantile-onset Pompe disease who presented coughing and respiratory distress. The infant experienced fatigue during breastfeeding from the birth and developed dry and nonproductive coughs and perioral cyanosis from two weeks after the birth. The echocardiogram demonstrated left and right ventricular enlargement, mitral and tricuspid regurgitation, and pulmonary hypertension. After definitive diagnosis, the patient was administered with $20 \mathrm{mg} / \mathrm{kg}$ of alglucosidase $50 \mathrm{mg}$ vial once every two weeks. He experienced significant improvement in body weight and echocardiogram and symptoms such as fatigue during breastfeeding and perioral cyanosis disappeared completely while he was under Myozyme treatment. In general, the observations confirmed the efficacy of Myozyme in a patient with infantile Pompe disease. Therefore, early diagnosis and quick treatment of Pompe disease with Myozyme can lead to acceptable outcomes, improve conditions, and finally, increase the chance of survival in these patients.

Keywords: Pompe disease; Infant; Myozyme
\end{abstract}

Received: 19 June 2018, Accepted: 9 March 2019, ePublished: 24 June 2019

\section{Introduction}

Pompe disease, also called type II glycogen storage disease, is a rare autosomal recessive inherited disease which is caused by the storage of glycogen in lysosome due to acid $\alpha$-glucosidase (GAA) deficiency (1). GAA deficiency causes the accumulation of glycogen in the cell and impairs the cell structure and function, leading to a multisystem disease and early death (2). The incidence rate of Pompe disease is very low and it occurs in less than one per one hundred thousand live births (3). As a clinical entity, the disease has been known for over 75 years. While an optimist might be excited about the advances made during this time, a pessimist would note that we have yet to find a cure (4). Pompe disease includes two major phenotypes, including infantile-onset and late-onset Pompe disease that differ in their characteristics based on the age at the onset, organ involvement, severity, and the rate of progression (5). Infantile-onset Pompe disease may manifest in utero but more often is diagnosed at 3-4 months of age with the findings of hypotonia, generalized muscle weakness, feeding difficulties, a failure to thrive, hearing loss, hypertrophic cardiomyopathy with systolic dysfunction, and respiratory distress. In addition, feeding difficulties may result from facial hypotonia, macroglossia, tongue weakness, and poor oral motor skills. The patients are likely to die within the first year of life $(6,7)$. There is no effective treatment for Pompe disease and the clinical control only includes the primary support health care. However, recent studies have reported that enzyme replacement therapy (ERT) can effectively reduce the symptoms or severity of the disease $(8,9)$. The reported case is the first case of Pompe disease in Chaharmahal and Bakhtiari who underwent enzyme therapy with Myozyme and responded to the treatment. The patient's conditions improved and he survived for more than one year.

\section{Case Presentation}

The patient was a 24-day infant who was referred from one of the counties of the province. The infant had been hospitalized due to coughing and respiratory distress and diagnosed with pneumonia and thus was treated with antibiotic therapy. During the examinations, 
echocardiography was conducted by an adult cardiologist and the patient was referred to our center due to left and right ventricular enlargement, mitral and tricuspid regurgitation, and pulmonary hypertension.

Due to the above-mentioned symptoms, the infant experienced fatigue during breastfeeding from the birth and developed dry and nonproductive coughs and perioral cyanosis since 2 weeks after his birth. In our center, electrocardiography (ECG) and echocardiography were ordered because cardiomegaly was observed in the chest X-ray (Figure 1).

The ECG showed increased voltage in most cardiac leads and decreased PR interval (Figure 2).

Further, the echocardiography demonstrated the enlargement and hypertrophy of both ventricles, atrial enlargement, mitral and tricuspid regurgitation, and pulmonary hypertension with SPAP $50 \mathrm{mmHg}$ (Figure 3).

As a result, treatment with lasix, sildenafil, and captopril was started to control pulmonary hypertension. Regarding the symptoms and examinations results, the suspected diagnosis was Pompe disease. The laboratory Pompe disease test conducted at the Pompe Disease Genetic Center in Tehran was sent to Germany and after 3 weeks, the positive Pompe disease test was received and the diagnosis was confirmed.

After the parents were informed, the infant underwent periodical treatment with Myozyme. In the first three administrations of the drug, the infant was hospitalized in our center and received the necessary health care. Because the family of the baby lived in one of the villages near Lordegan and it was difficult for them to commute to Shahrekord (the capital of the Province) the treatment was continued in Lordegan cunty. For the baby, $20 \mathrm{mg} / \mathrm{kg}$ bodyweight of alglucosidase $50 \mathrm{mg}$ vial was administered by intravenous infusion within 6 hours once every 2 weeks. The examinations demonstrated that the infant's conditions began to improve such that his weight reached $8.5 \mathrm{~kg}$ at 18 months of age while his birth weight was $3 \mathrm{~kg}$. The serial echocardiogram indicated that the left ventricular wall thickness of $12 \mathrm{~mm}$ reached 7-8 $\mathrm{mm}$. Moreover, the pulmonary pressure of $50 \mathrm{~mm} \mathrm{Hg}$ decreased to $30 \mathrm{~mm}$ $\mathrm{Hg}$ and the administration of drugs was discontinued and the symptoms such as fatigue during breastfeeding and perioral cyanosis disappeared completely.

\section{Discussion}

It is difficult to diagnose Pompe disease because of the rarity and relatively nonspecific nature of the phenotypic characteristics. Many diseases can be included in the differential diagnosis of Pompe disease such as idiopathic hypertrophic cardiomyopathy, myocarditis, spinal muscular atrophy type 1 , and congenital muscular atrophy (10). A high level of clinical suspicion is necessary for a timely and accurate diagnosis (11). Chest X-ray and electrocardiogram are the screening tests for diagnosing

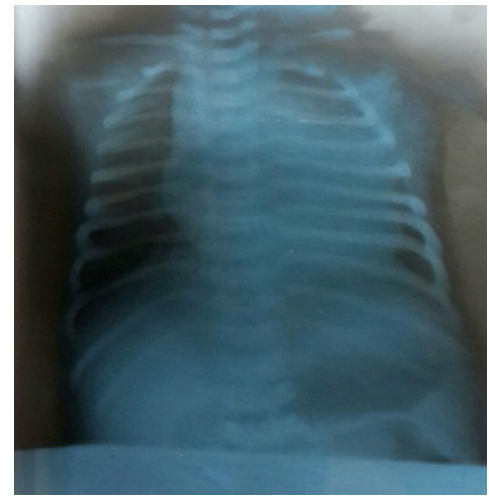

Figure 1. Chest $X$-ray.

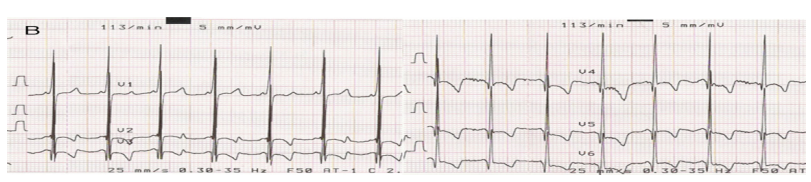

Figure 2. Pompe disease electrocardiography.

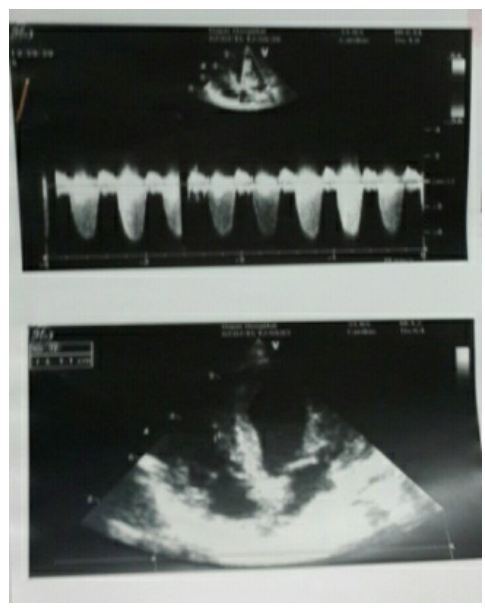

Figure 3. Initial echocardiography.

Pompe disease in infants. Echocardiography is the next diagnostic measure as well. Chest X-ray reflects the severity of cardiomegaly. ECG of these patients indicates short PR intervals and very tall QRS complexes. In a sample of 19 infants with Pompe disease, the PR intervals of 14 infants were short (12). In infants with Pompe disease, it is common to observe hypertrophic cardiomyopathy with or without the obstruction of left ventricular outflow tract in the early stages of the disease. In the final stages of the disease, dilated cardiomyopathy and cardiac dysfunction may be detected as well. Additionally, for patients with cardiomyopathy, an electromyogram can be useful for diagnosing myopathy before the emergence of the symptoms. The blood tests such as the measurement of blood creatine kinase are considered sensitive but nonspecific tests for Pompe disease (13). Taken together, the clinical diagnosis of the disease is confirmed by measuring 
$\alpha$-glucosidase in the tissues and the decline in its activity. Gene analysis is the gold standard for the diagnosis of Pompe disease. Conventional methods such as skin and muscle biopsies and dried blood spot test have certain limitations for the diagnosis of this disease. In recent years, prenatal diagnosis and newborn screening have played an important role in its early diagnosis (1). Pompe disease is regarded as a multisystem disease and a team including the cardiologist, pulmonologist, neurologist, physiotherapist, and speech therapist should cooperate with each other for its treatment (14). A number of clinical trials on Pompe disease in infants demonstrated that ERT can significantly increase the survival, decrease cardiomyopathy, and improve the functions of the heart and skeletal muscles in these patients (15-18). Without ERT, patients with infantile-onset Pompe disease develop cardiomegaly and hypertrophic cardiomyopathy that progress to left ventricular outflow obstruction, as well as systolic and diastolic dysfunction (6,7). The most optimal response of the skeletal muscles is reported in patients who are treated immediately and before the development of severe muscular injuries. However, some patients fail to satisfactorily respond to treatment despite starting quick treatment. It seems that certain factors such as the disease stage at the onset of the treatment and immune responses to the neo-compound enzyme contribute to the response to enzyme therapy (14). New targeted gene therapy and modified ERT will be put into practice in the future (1). Meanwhile, new trials in Pompe disease based on gene therapy are currently ongoing (19). However, the treatment of severe cardiac disease remains quite challenging (20-22).

Considering the role of genetics in Pompe disease, it should be noted that the parents of the case presented in this report were second-degree relatives, and after diagnosis confirmation, they were advised to receive genetic counseling before the next pregnancy.

The other family members of the patient were also suggested to attend genetic counseling sessions but they refused due to financial problems.

It is also recommended that genetic counseling be conducted for first-degree relatives before marriage, but it is not recommended for other consanguineous marriages due to the rarity of the disease and the lack of evidence on the incidence of the disease in the children of the other consanguineous couples.

\section{Conclusion}

Considering the favorable results of the treatment of the reported infantile Pompe disease with Myozyme, early diagnosis and quick treatment with Myozyme can bring about acceptable outcomes, improve the conditions, and increase survival in these patients.

Because the primary presentations of Pompe disease in infants are nonspecific and physicians have little information about this disease, the symptoms are frequently attributed to other diseases, which causes delayed diagnosis, and consequently, the treatment is not started early. Therefore, although Pompe disease is a rare one, the physicians should always consider this disease since the consequent cardiac and respiratory problems may lead to the death of the affected infants if they are not early diagnosed and treated with Myozyme.

Conflict of interests

None.

Ethical considerations

Not applicable.

References

1. Zhang XT, Ren WD. [Research advances in the diagnosis and treatment of Pompe disease]. Zhongguo Dang Dai Er Ke Za Zhi. 2018;20(7):588-93.

2. Ausems MG, Verbiest J, Hermans MP, Kroos MA, Beemer FA, Wokke JH, et al. Frequency of glycogen storage disease type II in The Netherlands: implications for diagnosis and genetic counselling. Eur J Hum Genet. 1999; 7(6):713-6. doi: 10.1038/ sj.ejhg. 5200367.

3. Fayssoil A. Cardiomyopathy in Pompe's disease. Eur J Intern Med. 2008;19(1):57-9. doi: 10.1016/j.ejim.2007.09.018.

4. Kohler L, Puertollano R, Raben N. Pompe disease: from basic science to therapy. Neurotherapeutics. 2018;15(4):928-42. doi: 10.1007/s13311-018-0655-y.

5. Kishnani PS, Beckemeyer AA, Mendelsohn NJ. The new era of Pompe disease: advances in the detection, understanding of the phenotypic spectrum, pathophysiology, and management. Am J Med Genet C Semin Med Genet. 2012;160c(1):1-7. doi: 10.1002/ajmg.c.31324.

6. Lloyd DF, Vara R, Mathur S. Cardiac manifestations of inherited metabolic disease in children. Pediatr Int. 2017;59(5):525-9. doi: 10.1111/ped.13272.

7. Chen M, Zhang L, Quan S. Enzyme replacement therapy for infantile-onset Pompe disease. Cochrane Database Syst Rev. 2017;11:Cd011539. doi: 10.1002/14651858.CD011539. pub2.

8. Kishnani P, Byrne B, Nicolino M, Mandel H, Leslie N, Hwu LH, et al. Enzyme replacement therapy (ERT) with recombinant human acid alpha glucosidase (rhGAA) in infantile onset Pompe disease (IOPD). J Inherit Metab Dis. 2005;28(Suppl 1):195

9. Winkel LP, Van den Hout JM, Kamphoven JH, Disseldorp JA, Remmerswaal M, Arts WF, et al. Enzyme replacement therapy in late-onset Pompe's disease: a three-year follow-up. Ann Neurol. 2004;55(4):495-502. doi: 10.1002/ana.20019.

10. Howell RR, Byrne B, Darras BT, Kishnani P, Nicolino M, van der Ploeg A. Diagnostic challenges for Pompe disease: an under-recognized cause of floppy baby syndrome. Genet Med. 2006;8(5):289-96. doi: 10.109701.gim.0000204462.42910. b8.

11. Guevara-Campos J, Gonzalez-Guevara L, Cauli O. Skeletal alterations, developmental delay and new mutations in juvenile-onset Pompe disease. Neuromuscul Disord. 2019;29(3):192-7. doi: 10.1016/j.nmd.2018.11.013.

12. Ansong AK, Li JS, Nozik-Grayck E, Ing R, Kravitz RM, Idriss SF, et al. Electrocardiographic response to enzyme replacement therapy for Pompe disease. Genet Med. 2006;8(5):297-301. doi: 10.109701.gim.0000195896.04069.5f.

13. Ausems MG, Lochman P, van Diggelen OP, Ploos van Amstel HK, Reuser AJ, Wokke JH. A diagnostic protocol for adult-onset glycogen storage disease type II. Neurology. 1999;52(4):851- 
3. doi: 10.1212/wnl.52.4.851.

14. Kishnani PS, Steiner RD, Bali D, Berger K, Byrne BJ, Case $\mathrm{LE}$, et al. Pompe disease diagnosis and management guideline. Genet Med. 2006;8(5):267-88. doi: 10.109701 . gim.0000218152.87434.f3.

15. Amalfitano A, Bengur AR, Morse RP, Majure JM, Case LE, Veerling DL, et al. Recombinant human acid alpha-glucosidase enzyme therapy for infantile glycogen storage disease type II: results of a phase I/II clinical trial. Genet Med. 2001;3(2):1328. doi: 10.109700125817-200103000-00007.

16. Klinge L, Straub V, Neudorf U, Schaper J, Bosbach T, Gorlinger $\mathrm{K}$, et al. Safety and efficacy of recombinant acid alphaglucosidase (rhGAA) in patients with classical infantile Pompe disease: results of a phase II clinical trial. Neuromuscul Disord. 2005;15(1):24-31. doi: 10.1016/j.nmd.2004.10.009.

17. Kishnani PS, Steiner RD, Bali D, Berger K, Byrne BJ, Case LE, et al. Pompe disease diagnosis and management guideline. Genet Med. 2006;8(5):267-288.

18. Winkel LP, Kamphoven JH, van den Hout HJ, Severijnen LA, van Doorn PA, Reuser AJ, et al. Morphological changes in muscle tissue of patients with infantile Pompe's disease receiving enzyme replacement therapy. Muscle Nerve.
2003;27(6):743-51. doi: 10.1002/mus.10381.

19. van Gelder CM, Poelman E, Plug I, Hoogeveen-Westerveld $M$, van der Beek N, Reuser AJJ, et al. Effects of a higher dose of alglucosidase alfa on ventilator-free survival and motor outcome in classic infantile Pompe disease: an open-label single-center study. J Inherit Metab Dis. 2016;39(3):383-90. doi: 10.1007/s10545-015-9912-y.

20. Broomfield A, Fletcher J, Davison J, Finnegan N, Fenton M, Chikermane A, et al. Response of 33 UK patients with infantileonset Pompe disease to enzyme replacement therapy. J Inherit Metab Dis. 2016;39(2):261-71. doi: 10.1007/s10545-0159898-5.

21. Matsuoka T, Miwa Y, Tajika M, Sawada M, Fujimaki K, Soga $T$, et al. Divergent clinical outcomes of alpha-glucosidase enzyme replacement therapy in two siblings with infantileonset Pompe disease treated in the symptomatic or presymptomatic state. Mol Genet Metab Rep. 2016;9:98-105. doi: 10.1016/j.ymgmr.2016.11.001.

22. Avula S, Nguyen TM, Marble M, Lilje C. Cardiac response to enzyme replacement therapy in infantile Pompe disease with severe hypertrophic cardiomyopathy. Echocardiography. 2017;34(4):621-4. doi: 10.1111/echo.13490. 